\title{
Strengthening Weak Healthcare Systems for Maternal and Neonatal Care in Low and Middle Income Countries: The Missing Link
}

\author{
Paul Nyongesa $^{1 *}$, Faith Yego ${ }^{2}$, Philiph Tonui ${ }^{1}$, Peter Itsura ${ }^{1}$, Bennad Sorre ${ }^{3}$, Egessah 0. Omar ${ }^{3}$ \\ ${ }^{1}$ Department of Reproductive Health, School of Medicine, Moi University, Eldoret, Kenya \\ ${ }^{2}$ Department of Health Policy, Management and Human Nutrition, School of Public Health, Moi University, Eldoret, Kenya \\ ${ }^{3}$ Department of Sociology, Psychology \& Anthropology, Moi University, Eldoret, Kenya \\ Email: ^drpaulnyongesa@yahoo.com
}

How to cite this paper: Nyongesa, $\mathrm{P}$., Yego, F., Tonui, P., Itsura, P., Sorre, B. and Omar, E.O. (2022) Strengthening Weak Healthcare Systems for Maternal and Neonatal Care in Low and Middle Income Countries: The Missing Link. Advances in Sexual Medicine, 12, 18-33.

https://doi.org/10.4236/asm.2022.121003

Received: November 12, 2021

Accepted: December 20, 2021

Published: December 23, 2021

Copyright $\odot 2022$ by author(s) and Scientific Research Publishing Inc. This work is licensed under the Creative Commons Attribution International License (CC BY 4.0).

http://creativecommons.org/licenses/by/4.0/

\begin{abstract}
Introduction: Preventable maternal and newborn mortalities still occur in local communities in Kenya since access to maternal and newborn healthcare services remains a big challenge. Barriers to access in resource-constrained settings have not been examined adequately in literature. The World Health Organization (WHO) has 6 building blocks for strengthening healthcare systems that informed this study. This paper examines how user-side and institutional factors influence access and use of Maternal and Newborn Healthcare $(\mathrm{MNH})$ Services in Matayos sub-County-Busia County. Methods: A mixed method approach, with an ethnographic inquiry and a descriptive cross-sectional design, was adopted to assess access to MNH services in Matayos-Busia County, Western Kenya. Postpartum women who had delivered within the previous 12 months and health care providers in the study area were recruited as respondents. A total of 348 postpartum women were selected through stratified systematic random sampling for the survey. Purposive sampling was used to select postpartum women, conventional and traditional health care providers for 16 in-depth interviews and 7 focus group discussions. Data were analyzed using descriptive and inferential statistics. Qualitative data analysis was done thematically. Results: Institutional delivery was low at $68 \%$ and family planning at $75 \%$ although demand for services was high at $99 \%$. User-side barriers to access included shared beliefs and practices in the community; high direct transport costs from home; and high costs for missing drugs and other supplies in hospitals. Middle $\left(5^{\text {th }}-7^{\text {th }}\right)$ order deliveries occurred at home with traditional birth attendants. The choice of place of delivery in households was influenced by spouses to respondents and communities of residence where respondents lived or were married. All 6 WHO health
\end{abstract}


system building blocks were weak in Matayos sub-County and needed system-wide strengthening involving all pillars. The user-community voice alone was insufficient and the $7^{\text {th }}$ pillar for user-community engagement was absent. The underlying factors were weak governance and underfunding for healthcare. Conclusion: The six WHO building blocks were inadequate due to weak governance and inadequate funding. User-community engagement, the $7^{\text {th }}$ Pillar, was absent in these resource-limited settings. We recommend user-community empowerment, engagement and participation, adoption of a system thinking approach and adequate funding.

\section{Keywords}

WHO Building Blocks, Low and Middle-Income Countries, Maternal and Newborn Health, Strengthening Health Systems, Community Engagement Pillar

\section{Introduction}

Strengthening health systems is expected to guide movement towards sustainable development goals for African countries [1]. However, current literature on healthcare system strengthening is characterized, not only by lack of how system performance is measured, but also by what constitutes health system strengthening [2]. Critical healthcare supply-side issues include weak governance and management of health resources; inadequate health management information systems, weak health infrastructure, shortage of health work force, inadequate health financing and poor quality healthcare services [3]. Moreover, there is no common conceptual framework for strengthening health system building blocks [4]. Infarct, healthcare systems vary widely and regions with similar levels of income, education and health expenditure differ in their ability to achieve given health goals [5] [6]. In many situations, interventions address only one or more of the building blocks and results tend to be short-lived. For sustainability and impact, the whole system needs to be addressed because different elements of the system are inter-connected and inter-dependent. Beliefs and worldviews, attitudes and feelings held, behaviors and cultures practiced by people in given communities enhance access and utilization of healthcare. The seventh pillar involving user-side community empowerment and engagement should not be ignored. It should be part of the essential building blocks. Building resilient health systems requires a systems-thinking approach with sets of interventions that cut across all the seven health systems building blocks including sufficient community engagement [7].

The objective of the study was to examine how user and institutional factors influence access and use of Maternal and Newborn Healthcare (MNH) Services in Matayos sub-County-Busia County. This study was guided by the WHO health system building blocks that form the backbone for provision of health 
services in health facilities [8]. The study assessed user perspectives on Leadership and Management of health facilities, Health Management Information System (HMIS), Health Workforce, Health Infrastructure, Health Finance, Maternal and Newborn Healthcare Services and Community Engagement. This covered the seven pillars of institutional blocks needed for strengthening health systems as suggested by many writers [9].

\section{Methods}

\subsection{Study Design}

A mixed method approach employing an ethnographic inquiry, with descriptive cross-sectional quantitative and explorative qualitative research techniques, was used in this study.

\subsection{Study Setting}

The study setting was Matayos sub-County-Busia County with a population of approximately 125,000 people in 5 wards; each with one or more community health units. The community health units were headed by one Community Health Extension Worker and served by 25 Community Health Workers for 5000 people.

\subsection{Study Population}

The study targeted 348 post-partum women who had delivered within the previous 12 months of the household visit and all health care providers in the study area from $19^{\text {th }}$ August 2015 to $2^{\text {nd }}$ March 2016. Health care providers included community health workers, traditional birth attendants, faith healers, herbalists, medicine men/women and conventional health care providers. Mothers were eligible if they were aged 18 to 49 . The informants were chosen because of their experience of access to services as either users or healthcare providers. A sample size for qualitative data was determined by the number required to achieve saturation and adequate variety while that for the quantitative segment was determined using "the small sample technique" by Krejcie and Morgan formula [10]. Systematic random sampling was adopted to select 348 women for quantitative data. Purposive sampling was used for 16 in-depth interviews and 7 focused group discussions to obtain qualitative data.

\subsection{Data Collection}

This study examined how user-side and institutional factors influenced access and use of Maternal and Newborn Healthcare (MNH) Services in Matayos sub-County, Busia County. Data were generated using interview guides and schedules. User perspectives on different elements of Leadership and Management of health facilities, Health Management Information System (HMIS), Health Workforce, Health Infrastructure, Medical Products and Technologies, Health Finance, MN Healthcare Services and Community Engagement were as- 
sessed as seen by users in Matayos sub-County.

\subsection{Data Analysis}

Qualitative data analyses were thematic derived from research objectives. Quantitative data were analyzed using STATA version 13. Results were summarized as frequencies and percentages using tables for quantitative data and vignettes for qualitative data.

Categorical variables were compared using Pearson's Chi Square test or Fishers exact test. Logistic regression was adopted for multivariable analysis using odds ratios and $95 \%$ confidence intervals. A p-value $<0.05$ was considered statistically significant.

\subsection{Ethical Consideration}

The study was approved by the Institutional Research and Ethics Committee at Moi University and Moi Teaching and Referral Hospital (IREC 0001387 dated $9^{\text {th }}$ April 2015).

\subsection{Results}

\subsubsection{Socio-Demographic Characteristics of Respondents}

The study targeted 348 post-partum women who had delivered within the previous 12 months of the household visit and all health care providers in the study area from $19^{\text {th }}$ August 2015 to $2^{\text {nd }}$ March 2016. Most women were aged 20-35 years (67\%), were married (87\%), had attained primary level of education $(74 \%)$, were Christians, lived with their spouses (84.8\%), and had 5-10 members in their households (50\%). The main occupation of these women was farming (49\%) with household earnings of Ksh 3000 - 10,000 (51\%). Their spouses had attained a primary level of education (63\%), were Christians (95\%), primarily working as casual laborers (43\%) (Table 1).

\subsubsection{Institutional Health Leadership and Management Pillar}

Health leadership and governance were top-down with centralized decision-making at National level without sufficient community engagement and public participation at sub-county level. The County Director of Health reported lack of community involvement in identification of problems, development of solutions and implementation of change in service delivery.

"under the new constitution the National Government was left with the issues of policy, standard operating procedures as well as capacity building, so in health we work with the national government policies... it s not easy for the community but at times we customize the national policies to suit the local people of Busia County". (The County Director of Health during an In-depth Interview)

\subsubsection{Maternal and Newborn Health Services Pillar}

Nearly three quarters $(263,75.6 \%)$ of the respondents rated attention to maternal 
Table 1. Socio-demographic characteristics of post-partum women respondents.

\begin{tabular}{|c|c|c|}
\hline Variable & Frequency $(\mathrm{N}=348)$ & Percent (\%) \\
\hline \multicolumn{3}{|l|}{ Maternal age } \\
\hline Less than 20 years & 61 & 18.0 \\
\hline $20-35$ Years & 232 & 67.0 \\
\hline Above 35 years & 55 & 15.0 \\
\hline \multicolumn{3}{|l|}{ Mother's education } \\
\hline None & 24 & 6.9 \\
\hline Primary & 258 & 74.0 \\
\hline Secondary & 59 & 17.0 \\
\hline Tertiary & 7 & 2.0 \\
\hline \multicolumn{3}{|l|}{ Spouse's education } \\
\hline None & 47 & 14.0 \\
\hline Primary & 219 & 63.0 \\
\hline Secondary & 75 & 22.0 \\
\hline Tertiary & 7 & 2.0 \\
\hline \multicolumn{3}{|l|}{ Level of education } \\
\hline Have same education & 238 & 68.3 \\
\hline Spouse has more education & 48 & 13.7 \\
\hline Spouse has less education & 22 & 6.2 \\
\hline Not sure & 40 & 11.5 \\
\hline \multicolumn{3}{|l|}{ Spouse's religious affiliation } \\
\hline Christian & 323 & 92.3 \\
\hline Muslim & 8 & 2.3 \\
\hline Traditionalists & 17 & 4.8 \\
\hline \multicolumn{3}{|l|}{ Marital status } \\
\hline Married & 303 & 87.0 \\
\hline Single & 37 & 11.0 \\
\hline Separated & 8 & 2.3 \\
\hline \multicolumn{3}{|l|}{ Stays with spouse } \\
\hline Yes & 295 & 84.8 \\
\hline No & 53 & 15.2 \\
\hline \multicolumn{3}{|l|}{ Household size } \\
\hline Below 5 & 46 & 13.0 \\
\hline $5-10$ & 175 & 50.0 \\
\hline Above 10 & 127 & 37.0 \\
\hline
\end{tabular}




\section{Continued}

\section{Occupation}

Farming (Peasant) only 168

49.0

Business Only

$68 \quad 20.0$

Casual Jobs Only

$36 \quad 10.0$

Formal Employment

$4-1.2$

Farming and other

Spouse's occupation

Casual jobs

Farming and other

Farming Only

Business Only

Not sure of spouse's occupation

Formal employment

Total monthly household income

$\begin{array}{lcc}\text { Not cash-dependent } & 68 & 20.0 \\ \text { Less than Ksh } 3000 & 46 & 13.0 \\ \text { Ksh } 3000-10,000 & 177 & 51.0 \\ \text { Above } 10,000 & 57 & 16.0\end{array}$

and newborn health services in the County as poor as said by respondents:

"The community should be given a chance to participate in the management of hospital affairs. The community health workers should also be recognized by the hospitals and allowed to talk to mothers on health issues...mothers would go to hospital and forced to disregard traditional birth attendants who accompanied them to hospital'. ( $A$ TBA during an FGD at Munongo)

\subsubsection{Health Management Information System (HMIS) Pillar}

All $(348,100 \%)$ respondents said they received information on $\mathrm{MNH}$ services in health facilities. Majority $(334,96 \%)$ of the respondents had received health talks by nurses. Other respondents had received messages through loudspeakers mounted on vehicles $(142,42.5 \%)$; listened to radios or watched televisions (82, $23.5 \%)$. Relatively few others, read health messages on posters on noticeboards $(28,8 \%)$ and billboards $(11,3.2 \%)$, or received short messages transmitted to their personal phones $(7,2 \%)$. Use of computers in management of health records in health facilities, was rated as "not useful" as evidenced by a mother who said:

“Computers cause a lot of delay in service delivery. Some women are delivered on hospital corridors by their accompanying traditional birth atten- 
dants while waiting for their files to be reflected on computers at the next service points". (A mother during a FGD at Mayenje)

\subsubsection{The Health Workforce Pillar}

The health workforce was a critical challenge for Matayos sub-County as narrated at a primary care facility

"Facilities remain closed during the weekends... Closure of dispensaries at night, outside working hours needs to be corrected urgently for the sake of mothers in labor. There are no health workers here at night and during weekends due to shortage of staff... mothers have to go to Matayos or Busia". (Husband during an FGD at Munongo)

Most respondents found health care providers to be experienced. This was said about doctors (318, 91.4\%); Nurses/Midwives (314, 90.2\%); Community Health Workers (341, 98.0\%) and Traditional Birth Attendants (279, 80.2\%). Most $(279,80.2 \%)$ i.e. 4 in 5, respondents described Faith Healers as not experienced compared to traditional attendants. Conventional health care providers were described as slow $(132,37.9 \%)$, harsh $(72,20.7 \%)$ and sometimes careless (Table 2).

A focus group discussion with traditional birth attendants noted that community health workers who were community owned resource persons, were not recognized at all by hospitals. Infarct, hospitals ignored their referral notes. As a result, clients in community units did not value community health workers; in contrast, traditional birth attendants and herbalists were well regarded. Nurses were regarded as "harsh".

\subsubsection{Health Infrastructure Pillar}

It was noted at the same FGD that:

"The health infrastructure was not well maintained. Medical equipment, medicines and other supplies were inadequate. Many facilities lacked piped water and electrical supply. The only sub-county hospital in the study area did not have an operating theatre and a supporting blood bank'.

\subsubsection{User-Side Factors and Use of Delivery Services}

Pregnancy or birth order of $1-2$ (OR 7.9, 95\% CI $(3.6-17.2), \mathrm{p}<0.001)$ and birth order of $3-5$ (OR $3.5,95 \%$ CI $(1.6-7.3), p=0.001)$ were associated with 8 times and more than 3 times odds of utilization of institutional deliveries respectively. There were higher odds of utilizing delivery services for women when husbands' birth positions did not influence decision making (OR 1.2, 95\% CI (1.1 - 1.4), $\mathrm{p}=0.002)$, and when the host communities influenced decision making (OR 7.9, 95\% CI (1.6 - 38.7), $\mathrm{p}=0.011)$.

Having shared views with other women (OR 4.8, 95\% CI $(2.9-7.9), \mathrm{p}<0.001)$ had 5 times increased odds of utilizing institutional delivery. Influence of husbands birth position (OR $0.7,95 \%$ CI $(0.5-0.9), \mathrm{p}=0.002)$, lack of influence of respondents natal community (OR $0.1,95 \%$ CI $(0.0-0.6), \mathrm{p}=0.011)$ and respondents' 
Table 2. Respondents Perspectives on Various Institutional Factors in Health Facilities in Matayos.

Variable

Frequency $(\mathrm{N}=348) \quad$ Percent $(\%)$

Institutional leadership and management of health facilities

Overall view of Institutional leadership and management of health facilities

$\begin{array}{lll}\text { Good } & 226 & 64.9 \\ \text { Poor } & 122 & 35.1\end{array}$

Attention to $\mathrm{MNH}$ services

Good $\quad 85$

Poor

Community Participation

Good

Poor

Community Partnerships

$\begin{array}{lcc}\text { Good } & 77 & 22.1 \\ \text { Poor } & 271 & 77.9\end{array}$

Delegation of tasks/services between and within health facilities

Good

Poor

Referral of tasks and services

$\begin{array}{lcc}\text { Good } & 338 & 97.1 \\ \text { Poor } & 10 & 2.9 \\ \text { Total } & 348 & 100.0\end{array}$

\section{Health Management Information System (HMIS)}

Do you receive any information on $\mathrm{MNH}$ services?

Yes

Source of information for MNH services
1. Nurses
2. Loudspeakers
3. Radio and TVs
4. Noticeboards
5. Billboards
6. Phones (Others)

Methods of delivery of information on MNH Services
1. Health Talks
2. Advert (Vehicle speaker)
3. Mass Media
4. Posters
5. Banners
6. Phone Messages

334

96.0

7 


\section{Continued}

\section{Health Workforce}

Views on skills and expertise of Doctors

Experienced

Not experienced

30

91.4

Views on skills and expertise of Nurses/Midwives

Experienced
Not experienced

Views on skills and expertise of Community Health Workers

Experienced

Not experienced

Views on skills and expertise of Traditional Birth Attendants

Experienced

Not experienced

Views on skills and expertise of Faith Healers

$\begin{array}{lcc}\text { Experienced } & 69 & 19.8 \\ \text { Not experienced } & 279 & 80.2 \\ \text { Total } & 348 & 100.0\end{array}$

views on TBAs as being experienced (OR 0.2, 95\% CI $(0.1-0.5), \mathrm{p}<0.001)$ had lesser odds of utilizing delivery services (Table 3 ).

Respondents, in a focus group discussion, were unanimous on expressing how inadequate the health infrastructure and supplies were. "Few beds, no electricity, no piped water, no drugs, no refrigerator, no laboratory and no houses for the nurses. ( $A$ husband during A FGD at Munongo)

\subsubsection{The Health Finance Pillar}

Treatment in health facilities in Matayos sub-County was never free as stipulated in government policy. Mothers spent about $50 \%$ of their monthly income on transportation to hospital, drugs and missing supplies if they or their newborns became sick once in a month. Seeking healthcare more than once in a month was said to be "catastrophic out of pocket expenditure" for majority of mothers and their newborns.

More than $40 \%(145,41.7 \%)$ had paid for maternal and newborn health services in the past. They paid for family planning $(66,19 \%)$, outpatient cards/books (57, $16.4 \%)$, antenatal care $(16,4.6 \%)$ and occasionally, for laboratory tests $(1,0.3 \%)$ and immunizations $(1,0.3 \%)$. In health centers and dispensaries, payments were made for laboratory tests, immunizations and delivery care services $(4,1.1 \%)$ when stocks were out. Even if you give birth, you still have to pay Kenya shillings 200 (equivalent 2 US Dollars) or the file and you have to buy other things which cost about Kenya shillings 1000 (equivalent 10 US Dollars) (Mothers during a FGD at Mayenje) after currency conversion from Kenya shillings to US Dollars. 
Table 3. Association between individual obstetric factors and use of delivery services.

\begin{tabular}{|c|c|c|c|c|}
\hline Individual Maternal obstetric factors & & N (\%) & $\operatorname{COR}(95 \% \mathrm{CI})$ & P-value \\
\hline \multirow[t]{3}{*}{ Pregnancy or Birth Order } & $3-5$ & $153(44)$ & $3.5(1.6-7.3)$ & 0.001 \\
\hline & $1-2$ & $157(45$ & $7.9(3.6-17.2)$ & 0.001 \\
\hline & 6 and above & $38(11)$ & 1 & \\
\hline \multirow[t]{3}{*}{ Source of delay } & Home & $52(15)$ & 1 & \\
\hline & Travel & $118(34)$ & $2.6(1.3-5.1)$ & 0.005 \\
\hline & Non-Specific & $178(51)$ & $6.8(3.5-13.3)$ & 0.001 \\
\hline \multirow[t]{2}{*}{ Influence of Husband's Birth position } & Yes & $67(19)$ & 1 & \\
\hline & No & $281(81)$ & $1.2(1.1-1.4)$ & 0.002 \\
\hline \multirow[t]{2}{*}{ Influence of Host Community } & No & $9(2.6)$ & 1 & \\
\hline & Yes & $339(97.3)$ & $7.9(1.6-38.7)$ & 0.011 \\
\hline \multirow[t]{2}{*}{ Shared views } & Yes & $257(74)$ & $4.8(2.9-7.9)$ & 0.000 \\
\hline & No & $91(26)$ & 1 & \\
\hline \multirow[t]{2}{*}{ Influence of Husband's Birth Position } & Yes & $67(19)$ & $0.7(0.5-0.9)$ & 0.002 \\
\hline & No & $281(81)$ & 1 & \\
\hline \multirow[t]{2}{*}{ Influence of Respondent's Host Community } & Yes & $243(70)$ & $0.6(0.4-1.0)$ & 0.062 \\
\hline & No & $105(30$ & 1 & \\
\hline \multirow[t]{2}{*}{ Influence of Respondent's Natal Community } & Yes & $9(3)$ & 1 & \\
\hline & No & $339(97)$ & $0.1(0.0-0.6)$ & 0.011 \\
\hline \multirow[t]{2}{*}{ Views on traditional birth attendants } & Experienced & $279(80)$ & $0.2(0.1-0.5)$ & 0.000 \\
\hline & Not experienced & $69(20)$ & 1 & \\
\hline \multirow[t]{2}{*}{ Views on Community Health Workers } & Experienced & $341(98)$ & $0.9(0.2-4.5)$ & 0.849 \\
\hline & Not experienced & $7(2)$ & 1 & \\
\hline
\end{tabular}

Note: P-Value, Probability Value, COR—Crude Odds Ratio, the significance level was set at a p-value of $<0.05$.

Direct costs on transport and indirect costs for missing supplies despite free maternity care was cited as a hindrance to health care access. There were lesser odds of utilizing services to as low as $40 \%$ for respondents who did not have to pay for maternal and newborn services (OR 0.4, 95\% CI $(0.2-0.6), \mathrm{p}<0.001)$.

Respondents who did not get information from the mass media (OR 0.5, 95\% CI $(0.3-0.8), \mathrm{p}=0.013)$ had $50 \%$ chances of not using health services. Respondents who thought doctors were experienced had nearly 4 times odds (OR 3.6, 95\% CI (1.7 - 7.8), $\mathrm{p}=0.001$ ) of utilizing institutional delivery services (Table 4).

\subsubsection{User-Side Voices}

Quantitative results reported as findings in this study indicated that majority $(271,78 \%)$ of the respondents did not participate in leadership, delivery and 
Table 4. Association between Health System Factors and use of Delivery Services in Matayos Sub-County, Busia County.

\begin{tabular}{|c|c|c|c|c|}
\hline VARIABLE & Response & $\begin{array}{l}\text { Frequency } \\
\text { n (\%) }\end{array}$ & $\begin{array}{c}\text { COR } \\
(95 \% \mathrm{CI})\end{array}$ & P-Value \\
\hline \multirow{2}{*}{$\begin{array}{l}\text { Institutional leadership and } \\
\text { management pillar }\end{array}$} & Good & $85(25.0)$ & 1 & \\
\hline & Poor & $263(75.0)$ & $0.8(0.5-1.4)$ & 0.405 \\
\hline \multirow{2}{*}{$\begin{array}{l}\text { Health Management Information } \\
\text { System Pillar (Mass Media as Source) }\end{array}$} & Yes & $79(23.0)$ & 1 & \\
\hline & No & $269(77.0)$ & $0.5(0.3-0.8)$ & 0.013 \\
\hline \multirow{2}{*}{$\begin{array}{l}\text { Health Finance Pillar (Payment for } \\
\text { MNH services) }\end{array}$} & Yes & $145(42.0)$ & 1 & \\
\hline & No & $203(58.0)$ & $0.4(0.2-0.6)$ & 0.001 \\
\hline \multirow{2}{*}{$\begin{array}{l}\text { Health Workforce Pillar (e.g. } \\
\text { doctors) }\end{array}$} & Not experienced & $30(9.0)$ & 1 & \\
\hline & Experienced & $318(91.0)$ & $3.6(1.7-7.8)$ & 0.001 \\
\hline \multirow[t]{2}{*}{ Health Infra-structure Pillar } & Adequate & $13(3.7)$ & & \\
\hline & Inadequate & $335(96.3)$ & $0.2(0.0-1.3)$ & 0.091 \\
\hline \multirow{3}{*}{$\begin{array}{l}\text { Health Services Pillar (Things not } \\
\text { liked) }\end{array}$} & none & $111(32.0)$ & $1.1(0.4-2.8)$ & 0.823 \\
\hline & Paying for services & $25(7.2)$ & 1 & \\
\hline & Slow staff & $140(40.0)$ & $0.7(0.3-1.8)$ & 0.079 \\
\hline
\end{tabular}

Note: P-Value, Probability Value, COR-Crude Odds Ratio, the significance level was set at a p-value of $<0.05$.

management of maternal and newborn health services in the study area. Majority of the respondents suggested having more staff (291, 83.5\%); more drugs (269, $77.3 \%)$ in health facilities and more health facilities $(260,74.7 \%)$ in the study area. Another significant proportion suggested more ambulances (126, 36.2\%); more friendly nurses $(117,32.7 \%)$ and free services $(52,14.9 \%)$ in public facilities. No user-side initiatives to service delivery were enumerated by any respondent of Matayos sub-county (Table 5).

\section{Discussion}

Governance of maternal and newborn healthcare was top-down without sufficient local community participation. The National Government issued health policy while Counties were only involved in policy implementation. Community participation and partnerships in MNH services were rated poorly by 8 in 10 of Matayos sub-County respondents. Community health workers and members of health committees were imposed on citizens without sufficient community engagement. Community participation and empowerment are meant to enhance responsiveness to people's needs and promote sustainable service provision to local communities. This has been confirmed to be the case in rural India and Nepal where use of antenatal and skilled birth attendance is universal [11]. It incorporates the power to identify, design and create own solutions to health challenges in the community as supported by evidence from Estonia [12]. This 
Table 5. Suggestions for improvement by mothers.

\begin{tabular}{lcc}
\hline Suggestions for improvement by mothers & Frequency $(\mathbf{n}=348)$ & Percent (\%) \\
\hline Add more staff & 291 & 83.6 \\
Add more drugs & 269 & 77.3 \\
Build more facilities & 260 & 74.7 \\
Avail ambulances at the health facilities & 126 & 36.2 \\
Nurses to be friendly & 114 & 32.7 \\
All services to be totally free & 52 & 14.9 \\
Provide free mosquito nets & 25 & 7.1 \\
Add more equipment & 19 & 5.4 \\
Install electricity & 9 & 2.6 \\
Build roads & 7 & 2.0 \\
Add more beds & 5 & 1.4 \\
Clean facilities & 2 & 0.5 \\
Separate children from adult wing & 1 & 0.3 \\
Piped water & 1 & 0.3 \\
Staff need to keep time & 1 & 0.3 \\
\hline
\end{tabular}

was not the case in Matayos sub-County although governance of the health management information system (HMIS) was rated as excellent.

It is notable that three quarters $(263,75.6 \%)$ of the respondents in Matayos rated attention to maternal and newborn health services in the County as poor. Quality of care in maternal and newborn health remained unsatisfactory. Respondents who did not get information from the mass media (OR 0.5, 95\% CI $(0.3-0.8), p=0.013)$ had $50 \%$ chances of not using health services. In contrast, respondents who thought doctors were experienced had nearly 4 times odds (OR 3.6, $95 \%$ CI $(1.7-7.8), p=0.001)$ of utilizing institutional delivery services.

The health management information system (HMIS) in Matayos sub-County was rudimentary and not well designed to support service delivery. This explains why respondents said computers were "not useful" in processing information at service delivery points. Well-functioning health information systems should ensure collection, analysis; production, dissemination and use of information on all the three essential domains of health system function, namely health system performance, environmental and socio-cultural determinants of health and health status of populations as suggested by Manyazewal [8]. This was not the case in Matayos sub-county.

A significant group of respondents had received health messages transmitted through loudspeakers mounted on vehicles $(142,42.5 \%)$, listened to radios or watched televisions $(82,23.5 \%)$ transmitting health messages through the mass media. However, relatively few others, had read health messages on posters on notice boards $(28,8 \%)$ and billboards $(11,3.2 \%)$, or received short messages transmitted to their personal mobile phones $(7,2 \%)$. Occasionally, some (11, 
$3.2 \%$ ), respondents got useful health talks from outreach talks mounted by healthcare providers during outreach visits to communities. From this, one would conclude that respondents valued messages they heard or watched rather than messages they read on notice boards and billboards. This is consistent with findings in oral cultures, as is the case in Africa, where the spoken word is more effective than the written word and documentation relatively more difficult to implement [13].

In-depth interviews and focused group discussions in this study revealed that all dispensaries were closed at night and on public holidays. Staff shortages were worse at night and on public holidays. This explains why dispensaries closed at such times and illustrates the important role of the health workforce. The health workforce remains the most important resource of the 4 health resources, the other 3 being: health infrastructure, health finance and health services [14]. A well-performing health workforce is one that works in ways that are responsive to the needs of the people [15]. Unfortunately, maternal and newborn health services in Matayos did not have the required resources and were not responsive to people's health needs.

Data gathered during interviews showed inadequate health infrastructure including medical equipment and supplies to be the weakest and the least developed health system building block in Matayos sub-County. "There were severe shortages of all types of health staff... the sick required out of pocket expenditure to travel to hospital and to buy missing supplies and reagents in health facilities in order to access health care". According to WHO's framework for action of 2007, health systems that function well need resource procurement and distribution systems that provide health services to those in need [16]. Efforts are made to bear on achieving better health outcomes, social security for all citizens and, most important, responsiveness to people's health needs.

Similarly, affordability of MNH services was rated as poor, with only 5 or less out of $10(61 \%)$ able to pay for services. Affordability presented serious psychosocial barriers to health access in Matayos for individuals who had "experienced discrimination and detention" in health facilities for failure to pay for health care as has been pointed by others authors elsewhere [17]. Governments in developing countries have acknowledged this problem and some have made it a priority to improve quality of care and make all health services more affordable [18]. This again was not the case in Matayos.

Cost has been reported to be a major deterrent in many research studies on access to health care. Both indirect and direct costs affect utilization of health services [19]. Health finance, therefore, could as well be the underlying cause of weakness in other pillars of the health system such as "severe staff shortages, poor health infrastructure, and lack of medicines and supplies" in Matayos sub-County. It was observed during this study that there were numerous private shops and pharmacies around most public health facilities in Matayos sub-County where clients paid directly for supplies missing in hospitals. 
Findings of this study also indicate that maternal and neonatal health services were uniformly available and on high demand in Matayos sub-County. Demand for $\mathrm{MNH}$ care was high as expressed by the number of women visiting hospitals for care (99\%), yet use of hospitals for delivery was only $68 \%$ and $75 \%$ for family planning. The other proportion of $25 \%$ to $32 \%$ did not access healthcare services and left with un-met needs to seek help elsewhere. The explanation is that maternal and newborn healthcare services were either not affordable in private hospitals or of poor quality in public health facilities which were poorly equipped. Accessibility was poor due to direct high transport costs from home and, sometimes indirect costs for missing drugs and supplies in hospitals. Services could not be accessed outside working hours in dispensaries; during rainy seasons with muddy roads; when the terrain was poor and were closed at night and on public hospitals. Maternal and newborn healthcare services were, in their current state, not acceptable to users in Matayos because of high costs and poor quality of care.

It is evident from these findings that users had concerns and demands, but did not realize that they needed to be partners in service delivery. This presents a major gap on the part of the users and health care providers in Matayos sub-County. Anu Kasmel, who studied Estonian Communities, recommended that empowered communities had responsibility to partner with the supply-side of healthcare in pursuit of good health [12]. This study, therefore, recommends further community engagement in Matayo sub-County in order to strengthen partnership between users and providers of MNH services and design culturally appropriate maternal and newborn healthcare services. The respondents needed to define their own role and the role of the community in strengthening health systems. This study recommends change in shared beliefs and practices by individuals, households in Matayos sub-County to enable community empowerment and followed by community engagement with the Busia County Directorate of Health for improved access and utilization of maternal and newborn healthcare services as recommended by some authors [20].

\section{Study Strengths and Limitations}

The study had both strengths and limitations. The choice of concurrent mixed method approaches, through the principle of triangulation [21], ensured increased validity and reliability of study findings. Adoption of an ethnographic inquiry design facilitated understanding of the all-important socio-cultural phenomenon common in low resource settings. However, the data were cross-sectional and cannot, therefore, be used to draw "causal" connections between outcome and predictor variables.

\section{Conclusion and Recommendations}

Culturally sensitive tailored interventions are required to influence shared beliefs and practices to inform policy to empower women so that they can access and 
utilize maternal and newborn healthcare.

\section{Acknowledgements}

The authors would like to thank Jack Odunga and Edwin Dindi for assistance with patient recruitment and for critiquing this manuscript.

\section{Conflicts of Interest}

The authors declare no conflicts of interest regarding the publication of this paper.

\section{References}

[1] Ibeneme, S., Ongom, M., Ukor, N. and Okeibunor, J. (2020) Realigning Health Systems Strategies and Approaches; What Should African Countries Do to Strengthen Health Systems for the Sustainable Development Goals? Frontiers in Public Health, 8, 372. https://doi.org/10.3389/fpubh.2020.00372

[2] Shakarishvili, G., Lansang, M.A., Mitta, V., Bornemisza, O., Blakley, M., Kley, N., Atun, R., et al. (2011) Health Systems Strengthening: A Common Classification and Framework for Investment Analysis. Health Policy and Planning, 26, 316-326. https://doi.org/10.1093/heapol/czq053

[3] Ergo, A., Eichler, R., Koblinsky, M. and Shah, N. (2011) Strengthening Health Systems to Improve Maternal, Neonatal and Child Health Outcomes: A Framework. US Agency for Development, Maternal and Child Health Integrated Program, Washington DC.

[4] Arah, O.A., Klazinga, N.S., Delnoij, D.M., Asbroek, A.T. and Custers, T. (2003) Conceptual Frameworks for Health Systems Performance: A Quest for Effectiveness, Quality, and Improvement. International Journal for Quality in Healthcare, 15, 377-398. https://doi.org/10.1093/intqhc/mzg049

[5] Murray, C.J. and Frenk, J. (1999) A WHO Framework for Health System Performance Assessment: Evidence and Information for Policy. World Health Organization, Geneva.

[6] Papanicolas, I., Woskie, L.R. and Jha, A.K. (2018) Healthcare Spending in the United States and Other High-Income Countries. JAMA, 319, 1024-1039.

https://doi.org/10.1001/jama.2018.1150

[7] McKenzie, A., Abdulwahab, A., Sokpo, E. and W Mecaskey, J. (2015) Building a Resilient Health.

[8] Manyazewal, T. (2017) Using the World Health Organization Health System Building through Survey of Healthcare Professionals to Determine the Performance of Public Healthcare Facilities. Archives of Public Health, 75, 50.

https://doi.org/10.1186/s13690-017-0221-9

[9] Tangcharoensathien, V., Limwattananon, S., Suphanchaimat, R., Patcharanarumol, W., Sawaengdee, K. and Putthasri, W. (2013) Health Workforce Contributions to Health System Development: A Platform for Universal Health Coverage. Bulletin of the World Health Organization, 91, 874-880.

https://doi.org/10.2471/BLT.13.120774

[10] Krejcie, R.V. and Morgan, D.W. (1970) Determining Sample Size for Research Activities. Educational and Psychological Measurement, 30, 607-610.

https://doi.org/10.1177/001316447003000308 
[11] Singh, P. and Yadav, R. (2000) Antenatal Care of Pregnant Women in India. Indian Journal of Community Medicine, 25, 112-117.

[12] Kasmel, A. and Tanggaard, P. (2011) Evaluation of Changes in Individual Community-Related Empowerment in Community Health Promotion Interventions in Estonia. International Journal of Environmental Research and Public Health, 8, 1772-1791. https://doi.org/10.3390/ijerph8061772

[13] Moody, L.E., Slocumb, E., Berg, B. and Jackson, D. (2004) Electronic Health Records Documentation in Nursing: Nurses' Perceptions, Attitudes, and Preferences. CIN: Computers, Informatics, Nursing, 22, 337-344. https://doi.org/10.1097/00024665-200411000-00009

[14] Kabene, S.M., Orchard, C., Howard, J.M., Soriano, M.A. and Leduc, R. (2006) The Importance of Human Resources Management in Health Care: A Global Context. Human Resources for Health, 4, 20-20. https://doi.org/10.1186/1478-4491-4-20

[15] Okyere, E., Mwanri, L. and Ward, P. (2017) Is Task-Shifting a Solution to the Health Workers' Shortage in Northern Ghana? PLoS ONE, 12, e0174631. https://doi.org/10.1371/journal.pone.0174631

[16] WHO (2007) Everybody's Business-Strengthening Health Systems to Improve Health Outcomes: WHO's Framework for Action.

[17] Noor, A.M., Zurovac, D., Hay, S.I., Ochola, S.A., Snow, R.W. and Noor, A.M. (2003) Defining Equity in Physical Access to Clinical Services Using Geographical Information Systems as Part of Malaria Planning and Monitoring in Kenya. Tropical Medicine \& International Health, 8, 917-926. https://doi.org/10.1046/j.1365-3156.2003.01112.x

[18] Dhar, R.S., Nagpal, J., Sinha, S., Bhargava, V.L., Sachdeva, A. and Bhartia, A. (2009) Direct Cost of Maternity-Care Services in South Delhi: A Community Survey. Journal of Health, Population, and Nutrition, 27, 368-378 https://doi.org/10.3329/jhpn.v27i3.3379

[19] Tibebe, A., Amarech, G., Melesse, T., Mariam, D.H., Amandua, J. and Olutoyin, G. (2010) Examining Out of Pocket Payments for Maternal Health in Rural Ethiopia: Paradox of Free Health Care Un-Affordability. Ethiopian Journal of Health Development, 26, 251-257

[20] Nyongesa, P., Kamaara, E., Ayanga, H.O., Mothaly, J., Akim, S.P., Ivy, S. and Lemons, J. (2020) Integrating Spiritual Care into Maternity Care at a University Teaching and Referral Hospital in Eldoret, Kenya: Challenges, Lessons and Way Forward. Health and Social Care Chaplaincy, 7, 168-215. https://doi.org/10.1558/hscc.37583

[21] McKim, C.A. (2017) The Value of Mixed Methods Research: A Mixed Methods Study. Journal of Mixed Methods Research, 11, 202-222.

https://doi.org/10.1177/1558689815607096 